\title{
入出力データ空間におけるデッドビート最適追従制御*
}

\author{
段一然 ${ }^{\dagger}$ 藤崎 泰正
}

\section{Dead-Beat Optimal Tracking Control in Input-Output Data Space*}

\author{
Yiran DUAN ${ }^{\dagger}$, Yasumasa FUJISAKI ${ }^{\ddagger}$ and Masao IKEDA ${ }^{\S}$
}

\begin{abstract}
The system representation in the input-output data space, which was proposed recently, leads to a new control strategy for a linear time-invariant plant. The control input is computed directly from the input-output data of the plant without using any traditional mathematical model, such as transfer function or state space equation. This paper considers a dead-beat tracking problem for arbitrary reference signals in that framework, and presents the optimal control for a quadratic performance index.
\end{abstract}

\section{1.はじめに}

我々が知り得る情報がシステムの入出力データである 場合を対象に，筆者らは，伝達関数, 状態方程式, kernel representation[1] などを用いない, 入出力データ空間に おけるシステム表現と制御方式 [2-5]を提案してきた.こ の枠組では, 入出力デー夕空間の基底を用いてシステム のダイナミクスを表現し, 直接, 望ましい入出力データ を構成して入力を決める.つまり, 入出力デー夕に基づ く従来研究 [6-10] とも異なり, 入出力デー夕空間で閉じ た新たなシステム制御理論の枠組を提供している.

さて，入出力デー夕空間におけるシステム表現を用い た一連の研究において, 筆者らは最短時間追従制御問 題 [2-4] や任意の有限時間における最適制御問題 [5] 考 察した.この参考文献 [5]では, システムの初期状態と

\footnotetext{
*原稿受付 1999 年 3 月 3 日

†神戸大学 大学院 自然科学研究科 (現在, 日本コンピュー夕 工業 (株)) Graduate School of Science and Technology, Kobe University; Rokkodai-cho 1-1, Nada ward, Kobe city, Hyogo 657-8501, JAPAN

‡神戸大学 工学部 Faculty of Engineering, Kobe University; Rokkodai-cho 1-1, Nada ward, Kobe city, Hyogo 657-8501, JAPAN

$\S$ 大阪大学 大学院 工学研究科 Graduate School of Engineering, Osaka University; Yamadaoka 2-1, Suita city, Osaka 565-0871, JAPAN

Key Words: discrete-time system, input-output data space, dead-beat optimal tracking, quadratic performance index, system representation.
}

終端状態に対応した入出力の時系列, すなわち, システ ムの次数と同じ長さの初期值系列と最終值系列を定義し, それら系列の双方あるいは片方を固定した最適制御問題 の解法を提案した。また, 定值への有限整定制御を念頭 に, 最終值系列としてシステムの望ましい平衡状態を指 定したい場合を想定し, それに対応した入出力の定值系 列の計算法を与えた.しかし, 任意の目標信号に出力を 完全に一致させるデッドビート追従制御問題では, 出力 の目標信号の長さは一般にシステムの次数に一致せず, 参考文献 [5] の入出力の最終值系列を与える問題には帰 着できない. したがって, 目標信号をそのまま出力の最 終值系列として指定でき, 直接解くことができるように, 入出力データ空間のアプローチを拡張する必要がある.

そこで本論文では, 任意の目標信号に対して出力を有 限時間で完全に一致させるデッドビート追従制御問題を， 参考文献 [5] で提案した枠組を拡張して考察する。まず, 次数と相対次数が既知であるとし, 入出力デー夕空間を 定義する.つぎに, 目標信号に対応する出力最終值系列 を定義し, デッドビート追従制御問題に整合する入出力 データ空間の構造を明らかにする. そして, 入出力デー 夕空間の構造に基づき, ある時刻以降で任意の目標信号 に出力が完全に一致するようなシステムの振舞いの中で, 2 次形式評価関数を最小とするものが, 入出力デー夕か ら直接計算できることを示す。なお，本文中で与えない 各定理の証明は，付録にまとめて与えている. 


\section{2. 入出カデータ空間の構造}

本論文では, 有限次元線形時不変の 1 入力 1 出力離散 時間システムを対象とする。このようなシステムは，

$$
\sum_{i=0}^{n} \alpha_{i} y_{k-i}=\sum_{i=r}^{n} \beta_{i} u_{k-i}
$$

なる差分方程式表現をもつ。ここで， $u_{k} \in \mathcal{R}, y_{k} \in \mathcal{R}$ は それぞれ時刻 $k$ での入力值, 出力值, $n, r$ はそれぞれ システムの次数, 相対次数であり, $n \geq r$ である. また, $\alpha_{i} \in \mathcal{R}, \beta_{i} \in \mathcal{R}$ は定数であり, $\alpha_{0} \neq 0, \beta_{r} \neq 0$ とする.

本論文では，このシステム $(1)$ の伝達関数は既約であ り, その次数 $n$ と相対次数 $r$ は既知であると仮定する. 一方, 定数 $\alpha_{i}, \beta_{i}$ の值は未知であるとし, その代わり に，このシステムが生成する入出力データ $y_{k}, u_{k}$ が十 分に入手できるとする。そして，それらデー夕に直接基 づいたシステム表現や制御方式を考察する。なお，相対 次数 $r$ が既知であることは, 任意の目標信号に出力を一 致させる入力が計算できるための必要条件である.

最初に, $\ell$ ステップの出力データと $\ell-r$ ステップの入 力デー夕を並べた次の入出カデータベクトルを考える.

$$
\begin{aligned}
z_{r}=\left[\begin{array}{llll}
y_{k} & y_{k+1} & \cdots & y_{k+\ell-1}{ }^{\prime} \\
u_{k} & u_{k+1} & \cdots & u_{k+\ell-r-1}
\end{array}\right]^{\mathrm{T}}
\end{aligned}
$$

ただし， $\ell>n$ とする.ここで, 参考文献 [5] とは異な $\eta$, 相対次数 $r$ に対応して時刻 $k+\ell-r-1$ までの入力 デー夕だけを並べるのは，それ以降の入力データが時刻 $k+\ell-1$ までの出力デー夕に影響を与えないためである.

対象システムが生成しうるすべての $z_{r}$ の集合は, 差分 方程式 (1) の線形拘束のもとで, 実べクトル空間 $\mathcal{R}^{2 \ell-r}$ の部分空間となる．以下ではこれを入出カデータ空間と 呼び， $\mathcal{Z}_{r}$ で表す。このとき, システム (1)の伝達関数が 既約であることょり，次の定理を得る。

\section{【定理 1】}

$$
\operatorname{dim}\left(\mathcal{Z}_{r}\right)=\ell+n-r
$$

つまり，任意の入出力データベクトル $z_{r}$ は $\mathcal{Z}_{r}$ の $\ell+$ $n-r$ 本の基底べクトルの線形結合で表すことができる から，これら基底ベクトルを対象システムの表現である と考えてよい. 以後, デッドビート追従制御問題を解く ことを目的として，この $\mathcal{Z}_{r}$ の構造を考察していこう.

まず，参考文献 [5] と同様に，(2) 式の入出力デー夕の 最初の $n$ ステップ分を初期值系列と呼ぶ. そして,

$$
\begin{aligned}
& z_{r F}=\left[\begin{array}{lllllll}
0 & \cdots & 0 & y_{k+n} & \cdots & y_{k+\ell-1}{ }^{\prime} \\
& 0 & \cdots & 0 & u_{k+n} & \cdots & u_{k+\ell-r-1}
\end{array}\right]^{\mathrm{T}}
\end{aligned}
$$

のような，初期值系列が 0 の入出力データベクトルを考 える.ただし， $\ell>n+r$ とする. 対象システムが生成し うるすべての $z_{r F}$ の集合を, 可到達データ空間と呼び, $\mathcal{Z}_{r F}$ で表す。このとき, システム (1)の伝達関数が既約 であることと, $\alpha_{0} \neq 0$ より, 次の定理を得る.

\section{【定理 2】}

$$
\begin{aligned}
& \operatorname{dim}\left(\mathcal{Z}_{r F}\right)=\ell-n-r \\
& \text { したがって, 入出力デー夕空間 } \mathcal{Z}_{r} \text { は, } \\
& \mathcal{Z}_{r}=\mathcal{Z}_{r I} \oplus \mathcal{Z}_{r F}
\end{aligned}
$$

と分解でき, 定理 1 と定理 2 より, この $\mathcal{Z}_{r I}$ の次元は

$$
\operatorname{dim}\left(\mathcal{Z}_{r I}\right)=2 n
$$

となる．つまり，任意の入出力データベクトル $z_{r}$ は，そ れと同じ初期值系列をもつ $z_{r I} \in \mathcal{Z}_{r I}$ と可到達デー夕空 間の要素 $z_{r F} \in \mathcal{Z}_{r F}$ を用いて,

$$
z_{r}=z_{r I}+z_{r F}
$$

と一意に表せる。

つぎに, 適当な自然数 $s$ を定め, (2) 式の出力データの 最後の $s$ ステップ分を出力最終值系列と呼ぶ.この出力 最終值系列は，デッドビート追従制御問題において，任 意に与える目標信号を表し, その長さは, 出力を完全に 一致させたい時間区間である。このように，出力のみの 最終值系列を考える点が, システムの終端状態に対応し た入出力の時系列として, システムの次数 $n$ の長さの最 終值系列を考えている参考文献 [5] とは異なる.

さて, 出力最終值系列が 0 の入出力データベクトル

$$
\begin{aligned}
z_{r P y}=\left[\begin{array}{llllll}
y_{k} & \cdots & y_{k+\ell-s-1} & 0 & \cdots & 0 \\
& u_{k} & u_{k+1} & \cdots & u_{k+\ell-r-1}
\end{array}\right]^{\mathrm{T}}
\end{aligned}
$$

を考えよう。ただし， $\ell>s$ とする. 対象システムが生成 しうるすべての $z_{r} \dot{P} y$ の集合を, 出力可制御データ空間 と呼び, $\mathcal{Z}_{r P y}$ で表す。このとき, システム $(1)$ の伝達関 数が既約であることと， $\beta_{r} \neq 0$ より，次の定理を得る.

\section{【定理 3】}

$$
\operatorname{dim}\left(\mathcal{Z}_{r P y}\right)=\ell+n-r-s
$$

したがって，入出力データ空間 $\mathcal{Z}_{r}$ は,

$$
\mathcal{Z}_{r}=\mathcal{Z}_{r T y} \oplus \mathcal{Z}_{r P y}
$$

と分解でき, 定理 1 と定理 $\mathbf{3}$ より, この $\mathcal{Z}_{r T y}$ の次元は

$$
\operatorname{dim}\left(\mathcal{Z}_{r T y}\right)=s
$$


となる.つまり, 任意の入出力データベクトル $z_{r}$ は, そ れと同じ出力最終值系列をもつ $z_{r T y} \in \mathcal{Z}_{r T y}$ と出力可制 御データ空間の要素 $z_{r P y} \in \mathcal{Z}_{r P y}$ を用いて,

$$
z_{r}=z_{r T y}+z_{r P y}
$$

のように一意に表すこともできる.

ここで，任意の目標信号に出力を有限時間で完全に一 致させるデッドビート追従制御問題が，初期状態に対応 した初期值系列と目標信号に対応した出力最終值系列を もつような入出力データベクトルを求める問題となるこ とに注意しょう．任意の初期值系列と任意の出力最終值 系列をもつ入出力データベクトルのすべてを $\mathcal{Z}_{r}$ が含む ためには，少なくとも，

$$
\operatorname{dim}\left(\mathcal{Z}_{r}\right) \geq \operatorname{dim}\left(\mathcal{Z}_{r I}\right)+\operatorname{dim}\left(\mathcal{Z}_{r T y}\right)
$$

であること，つまり $\ell \geq n+r+s$ である必要がある。そ こで, $\ell \geq n+r+s$ とすれば, システム (1) の伝達関数 の既約性と, $\alpha_{0} \neq 0, \beta_{r} \neq 0$ より，次の定理を得る.

\section{【定理 4】}

$$
\begin{aligned}
& \operatorname{dim}\left(\mathcal{Z}_{r P y} \cap \mathcal{Z}_{r F}\right)=\ell-n-r-s \\
& \text { したがって }, \ell \geq n+r+s \text { であるときには, } \\
& \operatorname{dim}\left(\mathcal{Z}_{r P y}+\mathcal{Z}_{r F}\right) \\
& \quad=\operatorname{dim}\left(\mathcal{Z}_{r P y}\right)+\operatorname{dim}\left(\mathcal{Z}_{r F}\right)-\operatorname{dim}\left(\mathcal{Z}_{r P y} \cap \mathcal{Z}_{r F}\right) \\
& =\operatorname{dim}\left(\mathcal{Z}_{r}\right)
\end{aligned}
$$

が成り立つ。これは，

$$
\mathcal{Z}_{r}=\mathcal{Z}_{r P y}+\mathcal{Z}_{r F}
$$

であることを意味している．そこで， $\ell \geq n+r+s$ のと きの入出力データ空間 $\mathcal{Z}_{r}$ を

$$
\mathcal{Z}_{r}=\mathcal{Z}_{r I P y} \oplus \mathcal{Z}_{r T y F} \oplus \mathcal{Z}_{r C y}
$$

と分解しておこう。ここで，

$$
\mathcal{Z}_{r C y}=\mathcal{Z}_{r P y} \cap \mathcal{Z}_{r F}
$$

である.また, $\mathcal{Z}_{r T y F} \subseteq \mathcal{Z}_{r F}, \mathcal{Z}_{r I P y} \subseteq \mathcal{Z}_{r P y}$ であり， それらの次元は, 定理 $2 \sim 4$ より,

$$
\operatorname{dim}\left(\mathcal{Z}_{r I P y}\right)=2 n, \quad \operatorname{dim}\left(\mathcal{Z}_{r T y F}\right)=s
$$

となる. (18) 式より, 任意の入出力データベクトル $z_{r}$ は，それと同じ初期值系列をもつ出力可制御データ空間 の要素 $z_{r I P y} \in \mathcal{Z}_{r I P y}$, それと同じ出力最終值系列をも つ可到達デー夕空間の要素 $z_{r T y F} \in \mathcal{Z}_{r T y F}$, 可到達かつ
出力可制御なデー夕空間の要素 $z_{r C y} \in \mathcal{Z}_{r C y}$ を用いて,

$$
z_{r}=z_{r I P y}+z_{r T y F}+z_{r C y}
$$

と一意に表せる。これを用いれば， 3. で述べるように， 入出力データ空間におけるシステム表現を用いて，デッ ドビート最適追従制御問題を解くことができる。

\section{3. 入出カデータ空間における追従制御}

それでは，以上のような入出力デー夕空間の構造に基 づき，任意の目標信号に対して出力を有限時間で完全に 一致させるデッドビート追従制御問題を, 有限時間の最 適制御問題として考察しょう。そのために，まず，次の 評価関数を導入する.

$$
J_{r}=\left(z_{r R}-z_{r}\right)^{\mathrm{T}} Q_{r}\left(z_{r R}-z_{r}\right)
$$

ここで, $z_{r} \in \mathcal{Z}_{r}$ は対象システムの生成する入出力デー夕 ベクトル， $z_{r R} \in \mathcal{R}^{2 \ell-r}$ はある参照データベクトルであ る. また, 正定行列 $Q_{r} \in \mathcal{R}^{(2 \ell-r) \times(2 \ell-r)}$ は重みである.

以下では， $\ell \geq n+r+s$ であるとする。まず，制御開 始時刻を $k+n$ とし, それより前の入出力デー夕が既知, すなわち初期值系列が決まっているとする，そして，時 刻 $k+\ell-s$ から $k+\ell-1$ までの出力をその目標信号, つ まり出力最終值系列に一致させることを考える. 2. での 議論より，与えられる初期值系列をもち出力最終值系列 が 0 の $\hat{z}_{r I P y} \in \mathcal{Z}_{r I P y}$ と, 与えられる出力最終值系列を もち初期值系列が 0 の $\hat{z}_{r T y F} \in \mathcal{Z}_{r T y F}$ は，それぞれ一 意に定まる。したがって，デッドビート最適追従制御問 題は次のように定式化できる.

【問題】 $z_{r R} \in \mathcal{R}^{2 \ell-r}, \hat{z}_{r I P y} \in \mathcal{Z}_{r I P y}, \hat{z}_{r T y F} \in$ $\mathcal{Z}_{r T y F}$ が与えられるとき，

$$
z_{r}=\hat{z}_{r I P y}+\hat{z}_{r T y F}+z_{r C y}
$$

と置き, $z_{r C y} \in \mathcal{Z}_{r C y}$ を適当に決めて, $(22)$ 式の評価関 数 $J_{r}$ を最小とする $z_{r o p t} \in \mathcal{Z}_{r}$ を求めよ.

このとき，(22) 式の $J_{r}$ を最小化する $z_{r C y o p t} \in \mathcal{Z}_{r C y}$ は， $\mathcal{R}^{2 \ell-r}$ における $\mathcal{Z}_{r C y}$ 上への $Q_{r}$-正射影行列 [11]

$$
P_{r C y}=H_{r C y}\left(H_{r C y}^{\mathrm{T}} Q_{r} H_{r C y}\right)^{-1} H_{r C y}^{\mathrm{T}} Q_{r}
$$

を用いて，

$$
z_{r C y o p t}=P_{r C y}\left(z_{r R}-\hat{z}_{r I P y}-\hat{z}_{r T y F}\right)
$$

と表せる.ここで, $H_{r C y}$ は $\mathcal{Z}_{r C y}$ の基底ベクトルをす べて並べたものである.したがって, 次の定理を得る.

【定理 5】 $z_{r R} \in \mathcal{R}^{2 \ell-r}, \hat{z}_{r I P y} \in \mathcal{Z}_{r I P y}, \hat{z}_{r T y F} \in$ $\mathcal{Z}_{r T y F}$ が与えられるとき, $(22)$ 式の評価関数 $J_{r}$ を $(23)$ 式の拘束のもとで最小化する $z_{r o p t} \in \mathcal{Z}_{r}$ は 
$z_{r o p t}=\left(I-P_{r C y}\right)\left(\hat{z}_{r I P y}+\hat{z}_{r T y F}\right)+P_{r C y} z_{r R}(26)$

で与えられ，それは一意である。

つまり,この $z_{\text {ropt }}$ の $u_{k+n}, u_{k+n+1}, \ldots, u_{k+\ell-r-1}$ に対応する要素が, 時刻 $k+n, k+n+1, \ldots, k+\ell-r-1$ で加えるべき入力である.

具体的に $z_{\text {ropt }}$ を求めるためには, 各デー夕空間 $\mathcal{Z}_{r I P y}, \mathcal{Z}_{r T y F}, \mathcal{Z}_{r C y}$ の基底べクトルが必要である. それらを既に得られている入出力データ $y_{i}, u_{i}$ から求 めるために, ブロックハンケル行列

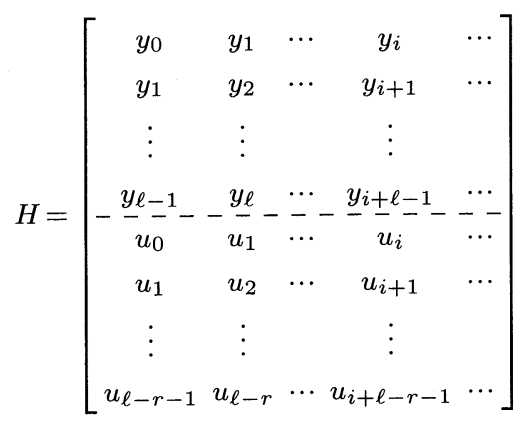

を構成する。十分多くの入出力データが得られている場 合, 定理 1 より, $H$ は $\ell+n-r$ 本の独立な列をもつ. そ れらを並べた行列を $H_{Z}$ とすれば, 次の定理を得る.

【定理 6】 $H_{Z}$ を基本列変換すれば,

$$
\left[\begin{array}{lll}
H_{r I P y} & H_{r T y F} & H_{r C y}
\end{array}\right]=\left[\begin{array}{cc|c|c}
I_{n} & 0 & 0 & 0 \\
* & * & * & * \\
0 & 0 & I_{s} & 0 \\
\hdashline 0 & I_{n} & 0 & 0 \\
* & * & * & *
\end{array}\right]
$$

とできる.ここで, $H_{r I P y}, H_{r T y F}$ と $H_{r C y}$ はそれぞ れ $\mathcal{Z}_{r I P y}, \mathcal{Z}_{r T y F}, \mathcal{Z}_{r C y}$ の基底を並べたものである。 この定理を用いれば， $P_{r C y}$ が具体的に構成できる.ま た, 時刻 $k+n$ より前に得られた入出力デー夕より, 初 期值系列ベクトル

$$
\begin{aligned}
x_{I}=\left[\begin{array}{llll}
y_{k} & y_{k+1} & \cdots & y_{k+n-1}{ }^{\prime} \\
u_{k} & u_{k+1} & \cdots & u_{k+n-1}
\end{array}\right]^{\mathrm{T}}
\end{aligned}
$$

を定義すれば，与えるべき $\hat{z}_{r I P y} \in \mathcal{Z}_{r I P y}$ は

$$
\hat{z}_{r I P y}=H_{r I P y} x_{I}
$$

と定まる. 一方, 出力最終值系列ベクトルとして, 出力 の目標信号

$$
x_{T y}=\left[\begin{array}{llll}
y_{k+\ell-s} & y_{k+\ell-s+1} & \cdots & y_{k+\ell-1}
\end{array}\right]^{\mathrm{T}}
$$

が指定されるとすれば，与えるべき $\hat{z}_{r T y F} \in \mathcal{Z}_{r T y F}$ は

$$
\hat{z}_{r T y F}=H_{r T y F} x_{T y}
$$

と定まる.これらと参照データベクトル $z_{r R}$ より, 定理 5 に従って， $z_{\text {ropt }}$ を求めることができる.

なお， $\ell=n+r+s$ とすれば, $\mathcal{Z}_{r C y}=\emptyset$ となるので, (23) 式の $z_{r}$ は一意に決まり, 最短ステップで目標信号 にデッドビート追従する振舞いとなる．このとき， $s=1$, つまり $\ell=n+r+1$ と決めて各時刻において入力を逐次 計算するものが, 参考文献 $[2,3]$ で提案している最短ス テップデットビート追従制御アルゴリズムの本研究の枠 組における表現となる。この場合, 無限時間での制御を 行うのなら，入力の系列が発散しないためには，制御対 象が最小位相系である必要がある $[2,3]$.

\section{4. 数值例}

それでは，提案した入出力データ空間におけるデッド ビート最適追従制御アルゴリズムを確認するため, 具体 的な数值例を示そう. ここでは, 次数が $n=2$, 相対次 数が $r=1$ である対象システム

$$
y_{k}+0.7 y_{k-1}+0.1 y_{k-2}=u_{k-1}-0.5 u_{k-2}
$$

を考える、そして，この対象システムのパラメータが未 知であるとし, その動作データから, 直接, デッドビー ト最適追従制御のための入力を計算する手順を示す。な お, 以下では, 入出力データベクトルで考慮するステッ プ数を $\ell=7$, 出力最終值系列のステップ数を $s=2$ と した場合を考える。

まず，対象システムに加えた入力の時系列

$$
\begin{array}{llll}
u_{0}=-1, & u_{1}=1, & u_{2}=-1, & u_{3}=1, \\
u_{4}=1, & u_{5}=-1, & u_{6}=-1, & u_{7}=1, \\
u_{8}=-1, & u_{9}=-1, & u_{10}=-1, & u_{11}=1, \\
u_{12}=1, & u_{13}=1, & u_{14}=1 &
\end{array}
$$

とそれにより発生した出力の時系列

$$
\begin{array}{lll}
y_{0}=0, & y_{1}=-1.00, & y_{2}=2.20, \\
y_{3}=-2.94, & y_{4}=3.34, & y_{5}=-1.54, \\
y_{6}=-0.75, & y_{7}=0.18, & y_{8}=1.45, \\
y_{9}=-2.53, & y_{10}=1.13, & y_{11}=-1.04 \\
y_{12}=2.11, & y_{13}=-0.88, & y_{14}=0.90
\end{array}
$$

の組が与えられたとする。これらのうち, 時刻 14 まで の出力デー夕と時刻 13 までの入力データを, $\ell=7$ とし た (27) 式の行列 $H$ に代入する。このとき， $H$ は $13 \times 8$ の列フルランクの行列となるので, その行列を $H_{Z}$ とす ることができる.したがって, 定理 6 より， $H_{Z}$ を

$$
\left[\begin{array}{lll}
H_{r I P y} & H_{r T y F} & H_{r C y}
\end{array}\right]
$$




$$
\left[\begin{array}{rrrr|rr|rr}
1 & 0 & 0 & 0 & 0 & 0 & 0 & 0 \\
0 & 1 & 0 & 0 & 0 & 0 & 0 & 0 \\
-0.10 & -0.70 & -0.50 & 1.00 & 0 & 0 & 0 & 0 \\
0 & 0 & 0 & 0 & 0 & 0 & 1 & 0 \\
0 & 0 & 0 & 0 & 0 & 0 & 0 & 1 \\
0 & 0 & 0 & 0 & 1 & 0 & 0 & 0 \\
0 & 0 & 0 & 0 & 0 & 1 & 0 & 0 \\
-0------- & - & - & - & - & - \\
0 & 0 & 1 & 0 & 0 & 0 & 0 \\
0 & 0 & 0 & 1 & 0 & 0 & 0 & 0 \\
-0.07 & -0.39 & -0.35 & 1.20 & 0 & 0 & 1 & 0 \\
-0.05 & -0.27 & -0.22 & 0.70 & 0 & 0 & 1.20 & 1 \\
-0.02 & -0.13 & -0.11 & 0.35 & 1 & 0 & 0.70 & 1.20 \\
-0.01 & -0.07 & -0.06 & 0.17 & 1.20 & 1 & 0.35 & 0.70
\end{array}\right]
$$

に変換することができる。そこで, 評価関数の重み行列を

$$
Q_{r}=\operatorname{blockdiag}\left\{I_{\ell}, 2 I_{\ell-r}\right\}
$$

と選ぶと, $Q_{r}$-正射影行列 $P_{r C y}$ は, $(24)$ 式より,

$$
\begin{aligned}
& P_{r C y}=\left[\begin{array}{rrrrrrr}
0 & 0 & 0 & 0 & 0 & 0 & 0 \\
0 & 0 & 0 & 0 & 0 & 0 & 0 \\
0 & 0 & 0 & 0 & 0 & 0 & 0 \\
0 & 0 & 0 & 0.25 & -0.16 & 0 & 0 \\
0 & 0 & 0 & -0.16 & 0.26 & 0 & 0 \\
0 & 0 & 0 & 0 & 0 & 0 & 0 \\
0 & 0 & 0 & 0 & 0 & 0 & 0 \\
0 & 0 & 0 & 0 & 0 & 0 & 0 \\
0 & 0 & 0 & 0 & 0 & 0 & 0 \\
0 & 0 & 0 & 0.25 & -0.16 & 0 & 0 \\
0 & 0 & 0 & 0.13 & 0.06 & 0 & 0 \\
0 & 0 & 0 & -0.02 & 0.19 & 0 & 0 \\
0 & 0 & 0 & -0.03 & 0.12 & 0 & 0
\end{array}\right. \\
& \left.\begin{array}{rrrrrr}
0 & 0 & 0 & 0 & 0 & 0 \\
0 & 0 & 0 & 0 & 0 & 0 \\
0 & 0 & 0 & 0 & 0 & 0 \\
0 & 0 & 0.49 & 0.26 & -0.05 & -0.06 \\
0 & 0 & -0.33 & 0.12 & 0.38 & 0.24 \\
0 & 0 & 0 & 0 & 0 & 0 \\
0 & 0 & 0 & 0 & 0 & 0 \\
0 & 0 & 0 & 0 & 0 & 0 \\
0 & 0 & 0 & 0 & 0 & 0 \\
0 & 0 & 0.49 & 0.26 & -0.05 & -0.06 \\
0 & 0 & 0.26 & 0.43 & 0.32 & 0.17 \\
0 & 0 & -0.05 & 0.32 & 0.42 & 0.25 \\
0 & 0 & -0.06 & 0.17 & 0.25 & 0.15
\end{array}\right]
\end{aligned}
$$

となる。

さて，参照データベクトルを

$$
z_{r R}=\left[\begin{array}{lllllllllll}
-1 & -0.5 & 0 & 0.5 & 1 & 0.5 & 0 & 0 & 0 & \cdots & 0
\end{array}\right]^{\mathrm{T}}
$$

とする.これは，三角波状の目標信号に，なるべく小さ い入力で追従する制御問題を考えることを意味する。い ま, 時刻 14 までの入出力データが与えられているので, 時刻 13 と 14 の入出力データを初期值系列とし, 時刻 15 から制御を開始することを考える。つまり，

$$
x_{I}=\left[\begin{array}{lll}
-0.88 & 0.90{ }^{\prime} 1 & 1
\end{array}\right]^{\mathrm{T}}
$$

である. また, 出力最終值系列は, $\ell=7, s=2$ である ので, $z_{r R}$ に含まれる目標信号の時系列から，

$$
x_{T y}=\left[\begin{array}{ll}
0.5 & 0
\end{array}\right]^{\mathrm{T}}
$$

である。これらを用いれば，定理 5 により,デッドビー 卜最適追従制御問題の解 $z_{\text {ropt }}$ は,

$$
\begin{array}{r}
z_{\text {ropt }}=\left[\begin{array}{rrrrrrrr}
-0.88 & 0.90 & -0.04 & -0.32 & -0.08 & 0.5 & 0 \\
1 & 1 & 0.24 & -0.19 & 0.32 & 0.50
\end{array}\right]^{\mathrm{T}}
\end{array}
$$

と求まる。つまり,

$$
\begin{aligned}
& u_{15}=0.24, \quad u_{16}=-0.19, \quad u_{17}=0.32, \\
& u_{18}=0.50
\end{aligned}
$$

が最適入力である。

\section{5.おわりに}

本論文では，入出力データ空間におけるシステム表現 を用いて，任意の目標信号に対するデッドビート最適追 従問題を解くことができることを示した。

まず，参考文献 [5] では対象システムの次数のみが既 知であると仮定しているのに対して，ここでは対象シス テムの次数と相対次数が既知であると仮定した，そして， この事前情報に合う入出力デー夕空間を考えた。また, 参考文献 [5] では入出力を共に目標信号に有限時間で一 致させる問題を考えているのに対して，ここではある時 刻以降で出力を任意の目標信号に完全に一致させる問題 を考えた. そして, この制御問題と整合するような入出 カデー夕空間の構造 (各部分空間) について考察した。こ のように, 入出力データ空間におけるシステム表現の枠 組では, 対象システムに関する事前情報や考える制御問 題に対応して, 適切に入出力デー夕空間とその構造を考 えることにより，種々の制御問題を解くことができる。

終りに，本研究に対して有益なコメントをいただいた 査読者に心より感飶します. また, 本研究の一部は, 平 成 $10 \sim 11$ 年度科学研究費補助金 (奨励研究 (A), 課題 
番号 10750344）より援助を受けました。ここに謝意を表 します。

\section{参考文献}

[1] J. C. Willems: Paradigms and puzzles in the theory of dynamical systems; IEEE Trans. on Automatic Control, Vol. 36, No. 3, pp. 259-294 (1991)

[2] 池田, 林：入出力データ蓄積によるディジタル制御 ; 第 16 回制御理論シンポジウム, pp. 47-50 (1987)

[3] 池田, 林, 藤崎：入出力デー夕蓄積によるモデルレス追従制 御アルゴリズム; 計測自動制御学会論文集, Vol. 34 , No. 6 , pp. 639-641 (1998)

[4] 藤崎, 段, 池田: 入出力デー夕配列に基づくシステム表現と 制御方式; システム制御情報学会論文誌, Vol. 11, No. 11, pp. 630-637 (1998)

[5] 藤崎, 段, 池田, 福田: 入出力デー夕空間におけるシステム表 現と最適制御；計測自動制御学会論文集, Vol. 34, No. 12 , pp. $1845-1853$ (1998)

[6] 河村: 入出力データから最適レギュレータを構成する基礎的 アルゴリズム; 計測自動制御学会論文集, Vol. 24, No. 11, pp. 1216-1218 (1988)

[7] K. Furuta and M. Wongsaisuwan: Discrete-time LQG dynamic controller design using plant Markov parameters; Automatica, Vol. 31, No. 9, pp. 1317-1324 (1995)

[8] R. E. Skelton and G. Shi: The data-based LQG control problem; Proc. of the 33rd IEEE Conference on Decision and Control, pp. 1447-1452 (1994)

[9] J. T. H. Chan: Data based synthesis of a multivariable linear quadratic regulator; Automatica, Vol. 32, No. 3, pp. 403-407 (1996)

[10] 杉江, 浜本: 入出力データに基づく最適制御入力の決定法一 凸計画法によるアプローチ; システム制御情報学会論文誌, Vol. 11, No. 2, pp. 86-92 (1998)

[11] 伊理, 韓: 線形代数一行列とその標準形, 教育出版, p. 230 (1977)

\section{付 録}

\section{付録 1. 定理 1 4 の証明}

最初に, $\ell>n$ であることに注意して，対象システム が満たすべき差分方程式 $(1)$ の係数を用いて,$(\ell-n) \times$ $(2 \ell-r)$ の行列

$$
\begin{aligned}
& \Theta_{r}=\left[\begin{array}{cccccr}
\alpha_{n} & \alpha_{n-1} & \cdots & \alpha_{0} & & 0 \\
& \ddots & \ddots & & \ddots & \vdots \\
0 & & \alpha_{n} & \alpha_{n-1} & \cdots & \alpha_{0}
\end{array}\right.
\end{aligned}
$$

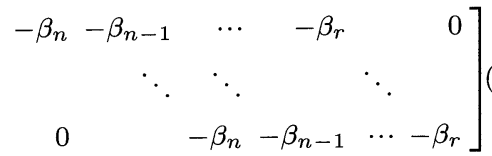

を定義すると，任意の入出力データベクトル $z_{r}$ に対して

$$
\Theta_{r} z_{r}=0
$$

が成り立つ. 対象システムの伝達関数の既約性より, 差
分方程式 (1) 以外に, 入出力に関する拘束条件が存在し ないので, (A2) 式は, 入出力データベクトル $z_{r}$ に対す るすべての拘束条件を表している.したがって，

$$
\mathcal{Z}_{r}=\operatorname{Ker} \Theta_{r}
$$

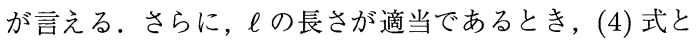
(9) 式に対応して

$$
\begin{aligned}
J_{r F} & =\text { block } \operatorname{diag}\left\{I_{n}, 0_{\ell-n}, I_{n}, 0_{\ell-n-r}\right\} \\
J_{r P y} & =\text { block } \operatorname{diag}\left\{0_{\ell-s}, I_{s}, 0_{\ell-r}\right\}
\end{aligned}
$$

を定義すると, 初期值系列や出力最終值系列が 0 系列で あるという拘束は，

$$
J_{r F} z_{r F}=0, \quad J_{r P y} z_{r P y}=0
$$

と書けるから，

$$
\begin{aligned}
\mathcal{Z}_{r F} & =\operatorname{Ker} \Theta_{r} \cap \operatorname{Ker} J_{r F} \\
\mathcal{Z}_{r P y} & =\operatorname{Ker} \Theta_{r} \cap \operatorname{Ker} J_{r P y} \\
\mathcal{Z}_{r C y} & =\operatorname{Ker} \Theta_{r} \cap \operatorname{Ker} J_{r P y} \cap \operatorname{Ker} J_{r F}
\end{aligned}
$$

が言える。ここで， $\alpha_{0} \neq 0 ， \beta_{r} \neq 0$ に注目すれば，

$$
\Theta_{r}, \quad\left[\begin{array}{c}
\Theta_{r} \\
J_{r F}
\end{array}\right], \quad\left[\begin{array}{c}
\Theta_{r} \\
J_{r P y}
\end{array}\right], \quad\left[\begin{array}{c}
\Theta_{r} \\
J_{r F} \\
J_{r P y}
\end{array}\right]
$$

の各行列のランクがそれぞれ $\ell-n, \ell+n, \ell-n+s$, $\ell+n+s$ あ゙あことがわかる.したがって，

$$
\begin{aligned}
\operatorname{dim}\left(\mathcal{Z}_{r}\right) & =\operatorname{dim}\left(\operatorname{Ker} \Theta_{r}\right) \\
& =2 \ell-r-\operatorname{rank} \Theta_{r} \\
& =\ell+n-r \\
\operatorname{dim}\left(\mathcal{Z}_{r F}\right) & =\ell-n-r \\
\operatorname{dim}\left(\mathcal{Z}_{r P y}\right) & =\ell+n-r-s \\
\operatorname{dim}\left(\mathcal{Z}_{r C y}\right) & =\ell-n-r-s
\end{aligned}
$$

であることがわかる、

\section{付録 2. 定理 6 の証明}

最初に, $H_{Z} \in \mathcal{R}^{(2 \ell-r) \times(\ell+n-r)}$ の行を適当に入れ換 えて, 初期值系列と出力最終值系列に対応する要素を上 の $2 n+s$ 行にまとめた行列 $\widehat{H}_{Z}$ をつくる. 定理 4 より $\mathcal{Z}_{r C y}$ の次元は $\ell-n-r-s$ なので, $\widehat{H}_{Z}$ を適当に基本 列変換すれば,

$$
\left[\begin{array}{cc}
\widehat{H}_{11} & 0 \\
\widehat{H}_{21} & \widehat{H}_{22}
\end{array}\right]
$$

とできる．明らかに $\widehat{H}_{11} \in \mathcal{R}^{(2 n+s) \times(2 n+s)}$ は正則行列 
である. 正則行列は基本列変換によって単位行列にする ことができ，最後に， $H_{Z}$ を $\widehat{H}_{Z}$ に変形したときに入れ

換えた行をもとの位置に戻せば，(28) 式の行列を得る. 